\title{
GMR
}

\section{Molecular analysis of patients suspected of Fragile X Syndrome}

\author{
A.P. Amancio ${ }^{1,2}$, C.A. de O. Melo ${ }^{1,2}$, A. de M. Vieira ${ }^{1,2}$, L.B. Minasi ${ }^{1,2}$, \\ D. de M. e Silva ${ }^{1,2,4}$, C.C. da Silva $a^{1,2,3}$ and A.D. da Cruz ${ }^{1,2,3}$ \\ ${ }^{1}$ Núcleo de Pesquisas Replicon, Departamento de Biologia, \\ Pontifícia Universidade Católica de Goiás, Goiânia, GO, Brasil \\ 2Programa de Pós-Graduação em Genética, \\ Pontifícia Universidade Católica de Goiás, Goiânia, GO, Brasil \\ ${ }^{3}$ Laboratório de Citogenética Humana e Genética Molecular, \\ Laboratório de Saúde Pública Dr. Giovanni Cysneiros, \\ Secretaria do Estado da Saúde de Goiás, Goiânia, GO, Brasil \\ ${ }^{4}$ Departamento de Biologia Geral, Instituto de Ciências Biológicas, \\ Universidade Federal de Goiás, Goiânia, GO, Brasil \\ Corresponding author: A.P. Amancio \\ E-mail: andreiaamancio5@gmail.com \\ Genet. Mol. Res. 14 (4): 14660-14669 (2015) \\ Received April 16, 2015 \\ Accepted July 13, 2015 \\ Published November 18, 2015 \\ DOI http://dx.doi.org/10.4238/2015.November.18.30
}

ABSTRACT. The aim of this study was to validate the molecular genetic diagnosis of patients suspected of Fragile $X$ Syndrome (FXS) in the Laboratory of Human Cytogenetics and Molecular Genetics (LaGene) of the Department of Health of the State of Goiás, using polymerase chain reaction (PCR). Thirty-five patients referred by public health doctors to LaGene, indicating clinical diagnosis of FXS, were selected for this study. Two PCR analyses were performed using different primers, one for screening (PCR-T) and one for the detection of the pre-mutation (PCR-P). The products of both PCRs were subjected to polyacrylamide gel electrophoresis and then coloring. The visualization of amplicons was performed with the aid of an ultraviolet transilluminator. The diagnosis was confirmed in $88 \%$ of patients with PCR-T and $100 \%$ with PCR-P. The primer used in PCR-P was 
found to be more sensitive and specific, allowing to identify the mutation in the samples, generating a more conclusive case for FXS, noting that the PCR-T is also required for the pre-classification of patients. Generally, the PCR technique is cheaper and easier to handle; therefore, we suggest the implementation of PCR in the genetics laboratory of the State of Goiás (LaGene) for the diagnosis of FXS.

Key words: Fragile X Syndrome; Intellectual disability; PCR; PCR-T; PCR-P

\section{INTRODUCTION}

Intellectual disability (ID) is the incomplete state or inhibited development of the intellect, which manifests before the age of 18. It is one of the greatest challenges of contemporary society, and is mainly characterized by a reduced quality of life. In general, disability imposes negative consequences for productivity and social relations in the population, causing inconvenience and unnecessary constraints to patients and their families (Vasconcelos, 2004; Galvan and Galvez, 2012).

Fragile $\mathrm{X}$ syndrome (FXS) is the most common, most researched, and best documented among the heritable IDs affecting humans (Ruiz et al., 2009). FXS is a genetic disorder that manifests several symptomatic developmental disorders, including learning disabilities, behavioral problems, pervasive developmental disorders, and autism and its related conditions (Hall et al., 2009). FXS is preceded only by trisomy 21 within the most common genetic etiology of intellectual disability (Yim et al., 2008).

Current estimates, based on a review of diagnostic cytogenetic methods for molecular analysis, showed an FXS prevalence rate of 1:4000 in men and 1:6000 in women. FXS is considered to be the second leading cause of hereditary and genetic etiology of ID, and (in this situation) is only surpassed by Down's syndrome (Lamonica et al., 2011).

From a genetic standpoint, FXS is a monogenic, recessive X-linked neurodevelopmental disorder resulting from alterations in the fragile mental retardation type 1 (FMR1) gene (located on the $\mathrm{X}$ chromosome; Xq27.3), with a penetrance of $60 \%$ in women and $80 \%$ in men (Figure 1). FXS is characterized by an unstable promoter region that is susceptible to expansion of a trinucleotide (CGG), contained in the 5'-untranslated region in the FMR1 gene (Van Esch, 2006; Kumari and Usdin, 2010; Cardozo and Soares, 2011).

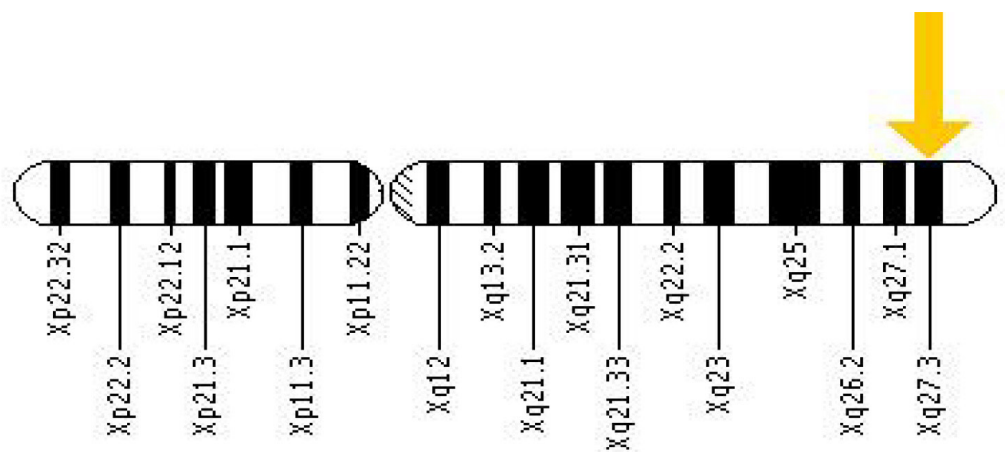

Figure 1. X-chromosome ideogram indicating the physical map of the FMR1 gene, located at Xq27.3. 
Normal individuals (who do not suffer from FXS) display approximately 6-50 repetitions, while affected individuals express up to 50-200 repetitions of the pre-mutation. Affected individuals express over 200 copies of the full mutation repeat, which results in inactivation of the gene, and consequent absence of its protein product (fragile X mental retardation protein; FMRP) (Yim et al., 2008; Hagerman et al., 2010).

The phenotypic manifestations of FXS are usually late; therefore, these are of little diagnostic value in children. On the other hand, the behavioral characteristics and cognitive manifestations occur early, and are more constant, thereby facilitating diagnosis of the disease (Collins et al., 2010).

Polymerase chain reaction (PCR) is among the most widely-used techniques for the identification of these changes; PCR is a sensitive, fast, and simple standard laboratory technique, which can be used to detect amplification of fragments in an individual with the syndrome (Stegani, 2011).

The test for diagnosis of FXS is one of the most requested screening tests for genetic diseases (Steiner et al., 2005), and the availability of an enhanced screening process benefits many patients. Rapid and accurate diagnosis, along with stimulation and early treatment, has a great influence on the prognosis of patients with FXS. Furthermore, the identification of affected individuals is important for genetic counseling of family members at risk of being carriers of the pre-mutation; in fact, secondary prevention measures, including prenatal diagnosis, would reduce the risk of recurrence, with subsequent reduction in institutional costs of public health (Bhogal and Jongens, 2010).

Therefore, this study aimed to validate the molecular genetic diagnosis of patients suspected of FXS in the Laboratory of Cytogenetics and Molecular Genetics (LaGene) of the Department of Health of the State of Goiás, using PCR.

\section{MATERIAL AND METHODS}

This study was developed in the Laboratory of Cytogenetics and Molecular Genetics (LaGene) of the Department of Health of the State of Goiás in Goiânia, with approval from the Ethics Committee of Pontifícia Universidade Católica de Goiás [Goiás CEP-SGC/PUC; Opinion No. 0039.0.168.000-19, approved on 15/09/2010 (Annex 2)]. Patients or their legal guardians were informed about the study, and signed an informed consent form. We selected 35 patients admitted to LaGene with clinical indications of FXS.

\section{Extraction and quantification of samples}

Biological samples (5.0 $\mathrm{mL}$ peripheral blood) were obtained from all patients in tubes containing EDTA. DNA extraction was performed using the kit Purelink ${ }^{\mathrm{TM}}$ Genomic DNA Mini Kit (Invitrogen, USA) according to the manufacturer protocol. DNA concentration for each specimen was quantified using the spectrophotometer NanoVue ${ }^{\circledR}$ Plus (GE Healthcare Life Sciences, USA), according to the manufacturer protocols.

\section{PCR protocol}

Two PCR techniques were perfomed and referred to herein as screening PCR (PCR-T) and PCR pre-mutation (PCR-P). They were used with adaptations, one was the substitution of one of the primers, suggested by the author, the initiator $F$ by the initiator 2 (Queiroz, 2011). 
The PCR-P method was named so because of its committed amplification of fragments up to $~ 330$ CGG repeats (full mutation of low expansion) in male patients, and fragments of up to $\sim 160$ CGG (pre-mutation) in females. These results are considered to be very satisfactory for the diagnosis of FXS.

This initial amplification of the FMR1 gene sequence of interest occurred in a final reaction volume of $25 \mu \mathrm{L}$, containing $50 \mathrm{ng}$ DNA, $0.5 \mathrm{mM}$ primer $\mathrm{C}, 0.5 \mathrm{mM}$ primer $\mathrm{F}, 10 \mu \mathrm{L} 5 \mathrm{X}$ Q-Solution (Qiagen), $200 \mathrm{mM}$ dNTPs, $2.5 \mu \mathrm{L}$ 10X PCR buffer, $2.5 \mathrm{mM} \mathrm{MgCl}_{2}$, and $1 \mathrm{U}$ Taq Platinum DNA polymerase (Invitrogen). The samples were amplified by denaturation at $94^{\circ} \mathrm{C}$ for $5 \mathrm{~min}$, followed by 35 cycles of denaturation at $94^{\circ} \mathrm{C}$ for $1 \mathrm{~min}$, annealing at $60^{\circ} \mathrm{C}$ for $1 \mathrm{~min}$, extension at $72^{\circ} \mathrm{C}$ for 1 $\mathrm{min}$, and a final extension at $72^{\circ} \mathrm{C}$ for $7 \mathrm{~min}$. To standardize the protocol and amplify the large premutations, we made modifications to the original protocol of Khaniani et al. (2008). The annealing temperature was changed from $70^{\circ} \mathrm{C}$ to $60^{\circ} \mathrm{C}$, the annealing time altered from $45 \mathrm{~s}$ to $1 \mathrm{~min}$, and the volume of $\mathrm{Q}$-solution (Qiagen) varied from 8 to $10 \mu \mathrm{L}$, allowing for greater amplification of the repetitions. The final size of the expected PCR product was approximately $300 \mathrm{bp}$, where the normal values for men and women are approximately 300 and $325 \mathrm{bp}$. The second reaction was performed with a final volume of $30 \mu \mathrm{L}$, containing $50 \mathrm{ng}$ DNA, $0.5 \mathrm{mM}$ primer $\mathrm{C}, 0.5 \mathrm{mM}$ primer 2, $10 \mu \mathrm{L} 5 X$ Q-Solution (Qiagen), $200 \mathrm{mM}$ dNTPs, $2.5 \mu \mathrm{L} 10 \mathrm{X}$ PCR buffer, $2.5 \mathrm{mM} \mathrm{MgCl}$, and $1 U$ Taq Platinum DNA polymerase (Invitrogen). The samples were amplified using the following reaction conditions: denaturation at $94^{\circ} \mathrm{C}$ for $5 \mathrm{~min}, 35$ cycles of denaturation at $94^{\circ} \mathrm{C}$ for $1 \mathrm{~min}$, annealing at $61^{\circ} \mathrm{C}$ for $1 \mathrm{~min}$, extension at $72^{\circ} \mathrm{C}$ for $1 \mathrm{~min}$, and a final extension at $72^{\circ} \mathrm{C}$ for $7 \mathrm{~min}$. The final size of the expected PCR product was approximately 200 bp for normal men, and 200 to 225 for normal women. The primer sequences are presented in Table 1.

Table 1. Primers used in the amplification of alleles of the FMR1 gene by PCR-T and PCR-P.

\begin{tabular}{lclc}
\hline Technique & Primers & Sequence 5' $\rightarrow 3^{\prime}$ & Expected size of the amplified product \\
\hline PCR-T & C & GCTCAGCTCCGTTTCGGTTTCACTTCCGGT & $198+3 \mathrm{n}$ \\
& 2 & TCCTCCATCTTCTCTTCAGCCCT & $221+3 \mathrm{n}$ \\
PCR-P & C & GCTCAGCTCCGTTTCGGTTCACTTCCGGT & \\
& F & AGCCCCGCACTTCCACCACCAGCTCCTCCA & \\
\hline
\end{tabular}

\section{Polyacrylamide gel electrophoresis (PAGE)}

The products of both PCR cycles were subjected to gel electrophoresis on an $8 \%$ polyacrylamide gel. Fifteen microliter of the PCR product, together with $5 \mu \mathrm{L}$ Fast Green dye (Invitrogen) was applied to this gel. The samples were electrophoresed at $100 \mathrm{~V}$ for approximately $3 \mathrm{~h}$ with $1 \mathrm{X}$ TBE (Tris Borate-EDTA) buffer. We also included a marker for increased molecular weight of $100 \mathrm{bp}$ in the gel, which was used for subsequent fragment size analysis.

Following the electrophoresis procedure, the polyacrylamide gel was stained with a DNA intercalating compound (ethidium bromide) for visualization; the results were visualized using a UV transluminator.

As the fragment size was presented in base pairs (bp), it was possible to calculate the approximate value of the number of CGG repeats present in each sample; this was subtracted from the value generated from the amplification product without the trinucleotide CGG, which is the sum of the number of bases in each primer, and the number of bases flanking the region of CGG repeats of the FMR1 gene. 
The diagnosis is defined by the number of CGG repeats, which helps categorize the patients based on the FXS classification into normal, gray zone, pre-mutated, or affected (Table 2). The diagnosis might be inconclusive when women present only one amplicon, or men show no amplicons. In such cases (beyond inconclusive, but suggestive of the presence of a full mutation), the patient was believed to be affected by the syndrome.

Table 2. Representation of the size of expected fragments after PCR-T and PCR-P.

\begin{tabular}{|c|c|c|c|c|}
\hline \multirow[t]{2}{*}{ Classification } & \multicolumn{2}{|c|}{ PCR-T } & \multicolumn{2}{|c|}{ PCR-P } \\
\hline & $\delta(\mathrm{bp})$ & 우 (bp) & $\delta(\mathrm{bp})$ & ㅇ (bp) \\
\hline Normal & $\sim 300^{*}$ & 300 and 325 & $\sim 200$ & 200 and 225 \\
\hline Zona gray & 400 & 300 and 400 & 300 & 200 and 300 \\
\hline Inconclusive & - & 300 & - & 200 \\
\hline Pre-mutation & - & - & 600 & 300 and 600 \\
\hline
\end{tabular}

${ }^{*} \mathrm{bp}=$ base pairs.

\section{Data analysis}

The data obtained in this study was subjected to nonparametric statistical testing. The samples were tested by Fischer analysis in order to determine the significance of differences between the two groups.

\section{RESULTS}

The results from the analysis of blood samples obtained from 35 patients with clinical indications of FXS by the two PCR methods, PCR-T and PCR-P, were classified into two groups: conclusive and inconclusive. The diagnosis was defined as conclusive when the products resulting from the amplification of the specific region of the FMR1 gene showed an allele in male patients, or two alleles in females. Results that showed no amplification or amplification of only one allele in female patients were classified as inconclusive.

For a conclusive result, female patients must obligatorily display the presence of two alleles. This is because of the presence of two $X$ chromosomes in the female genome. Men, because they have only one $X$ chromosome in their genome, amplify only one allele of the FMR1 gene. In this case, the absence of amplification leads to an inconclusive diagnostic result, suggesting that the patient is affected by the syndrome.

The results show a significant improvement in the diagnostic conclusiveness, when analyzed by PCR-P. Among the studied cases, 88 and $100 \%$ were found to be inconclusive when analyzed by PCR-T and PCR-P, respectively (Figure 2).

When analyzed by PCR-T, 4 patients were classified as inconclusive; two of these were female and 2 male. The only patient classified as inconclusive by PCR-P was male.

The increased rate of conclusive diagnoses by PCR-P in female patients occurred because the amplification efficiency of corresponding alleles was observed in the gray zone, and pre-mutation and improvement amplification of two alleles was observed in the normal range.

The analysis of 35 samples by PCR-T resulted in $88 \%$ conclusive results, while PCR-P resulted in a $100 \%$ conclusive diagnosis. The PCR-P showed vast improvement and greater efficiency in the amplification of alleles in the analyzed patients. Despite the low number of female 
samples $(N=3)$, the result signified the conclusiveness of the test for this group. Statistical analyses of all results obtained from the PCR-P and PCR-T did not show any significant value when subjected to the Fisher test $(p>0.11)$. This test was used to analyze the significance of changes in the related samples.

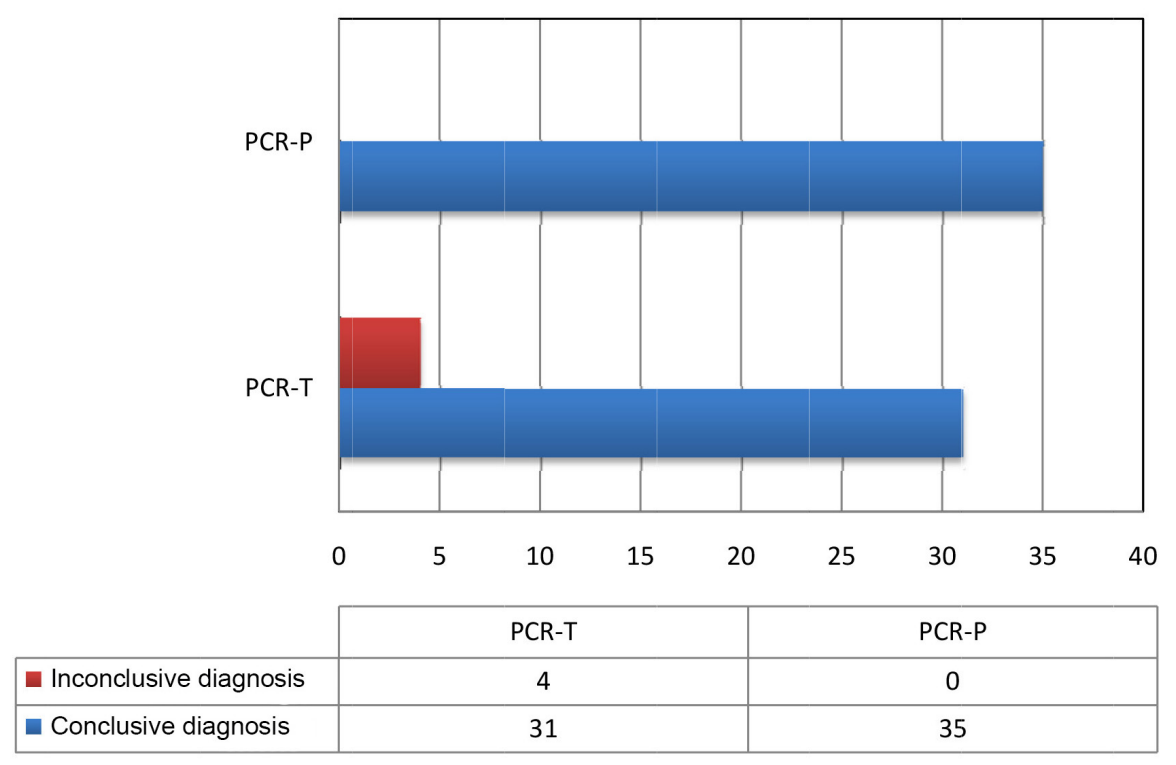

Figure 2. Comparison of the PCR for pre-mutation (PCR-P) and PCR screening (PCR-T) techniques for the diagnosis of patients with clinical indication of fragile $X$ syndrome. Horizontal bars show the percentage of inconclusive and conclusive diagnoses for all patients, with the number of cases shown in the adjacent table.

These results were expected because of the size of the sample group and the small variations in the conclusiveness of each technique. Although the results were not statistically significant, they indicated a substantial impact on the patient's family.

Although the numbers did not appear significant, classification into the zone and gray matter pre-mutation resulted in a definitive diagnosis for each patient. Therefore, we highlighted the importance of this test, especially in cases of pre-mutation, as these can transmit the full mutation to future generations. For patients diagnosed into the gray zone by PCR-P, the definition of diagnosis is also important as it determines the treatment utilizedin each case.

The number of CGG repeats and alleles of patients studied by PCR-T and PCR-P were variable in some cases. Of the 35 samples analyzed, 19 (54\%) showed some variation in the number of CGG repeats. These variations occurred on a small scale; in such cases, the difference was only one or two CGG repeats, or median (variations) of the second CGG. The major difference found was 10 CGG repeats; however, we observed no changes in the classification and diagnosis of the patient.

Only in three cases did the classification of the patient varies; one was classified into the gray normal area, while the other two were classified into the inconclusive area for normal and pre-mutation. However, in these cases,the alleles ranged from 37 to 40 repetitions of CGG, as determined by PCR-T and PCR-P, respectively. These results were similar to those observed by Filipovic et al. (2010), where such change was observed in only two samples (Figures 3 and 4). 
Among the cases studied, the variations in the number of CGG repeats of the same allele analyzed by both techniques proved to be stable and reliable.

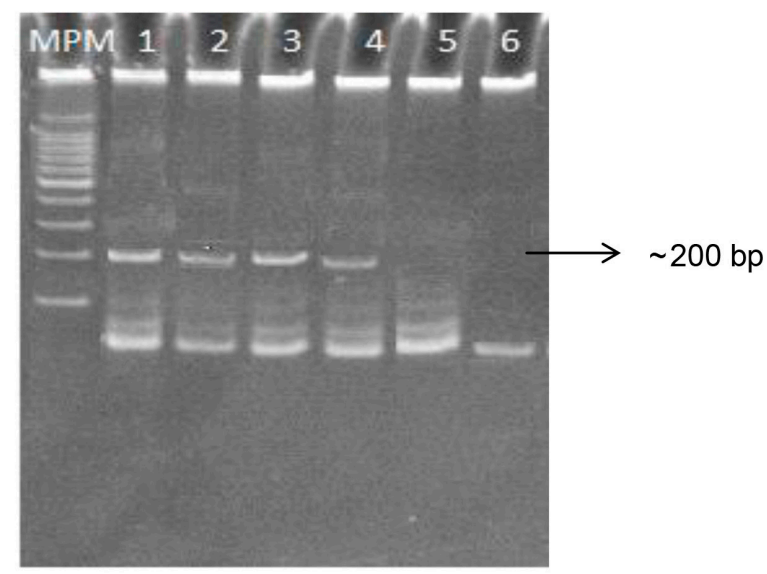

Figure 3. Visualization of fragments amplified by PCR-T in the polyacrylamide gel. Alleles of inconclusive females are located in lanes 1 and 2. Normal alleles of male patients are in lanes 3 and 4, inconclusive result of a single male patient indicated by lane 5 , and the white control in lane 6. "MPM" refers to the molecular weight marker, and "bp" indicate the base pairs.

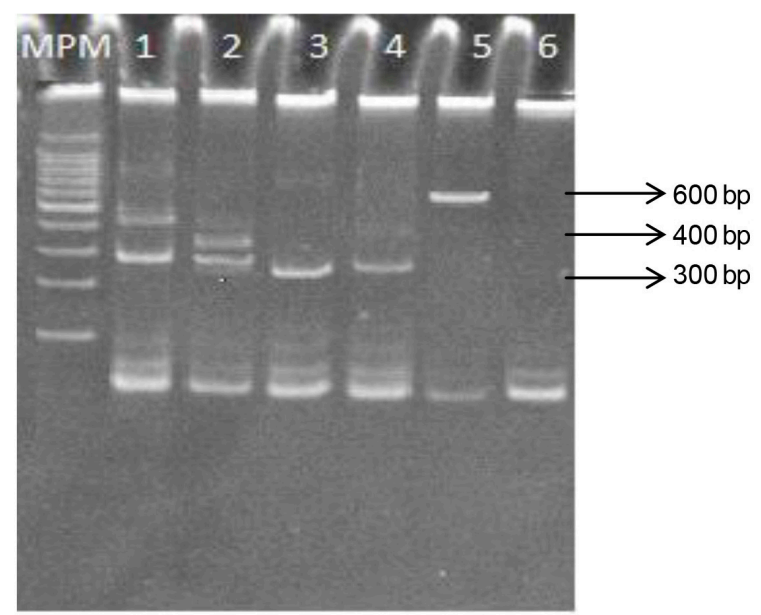

Figure 4. Visualization of fragments amplified by PCR-P and separated in a polyacrylamide gel. Gray zone alleles and normal female alleles are located in lanes 1 and 2. Normal alleles of male patients are in lanes 3 and 4; pre-mutated alleles in male are in lane 5, and white control shown in lane 6. "MPM" refers to the molecular weight marker and "bp" indicates the base pairs.

\section{DISCUSSION}

The clinical and laboratory diagnosis of FXS follows international guidelines, and recommendations for laboratory diagnosis, including PCR tests for initial screening, and a combination of PCR with other molecular techniques when necessary. 
The results in this study show a significant improvement in the diagnostic conclusiveness when the samples were analyzed by PCR-P. Among the studied cases, 88 and $100 \%$ were found to be inconclusive when analyzed by PCR-T and PCR-P, respectively.

Queiroz (2006) obtained a result similar to this study, where the PCR-P proved to be more sensitive for the diagnosis of FXS. This technique has shown a vast improvement and greater efficiency in the amplification of alleles in the analyzed patients. However, no significant and conclusive variation was observed in the female patients $(N=3)$, because of the low number of samples compared to those of males.

Clearly, the use of PCR-P was advantageous compared to a screening technique for the detection zone and gray pre-mutated samples, as only a few cases were reported by the conclusive diagnosis sorting technique (in fact, none of the female samples were registered in the pre-mutated group). It was observed that PCR-P could positively diagnose pre-mutations that were undetectable when analyzed by PCR-T, although the results of this study were more evident in male patients. It is important to remember that, while PCR-T does not detect patients with premutation (which is an intrinsic limitation of the technique), PCR-P analyses detected up to 330 CGG repeats in men and 160 in women (Saluto et al., 2005).

Based on the results of our study, we have proposed a diagnostic strategy, including PCR for pre-mutation as the preferred technique for screening men and women with clinical suspicion and/or family history of FXS.

We suggested analyzing the expansion of CGG repeats in the FMR1 gene in women with clinical suspicion and/or family history of the syndrome by screening with PCR-P. If the results remained inconclusive, further familial research was suggested, as the disease is hereditary, X-linked, with all affected individuals carrying an ascending pre-mutation carrier.

PCR-P analysis of parents of female patients may discard or emphasize the suspicion of FXS. If parents are normal for the mutation in the FMR1 gene, the patient can be concluded to be normal.

The analysis of maternal and paternal genes in patients testing inconclusive, or displaying the presence of a pre-mutation, requires a more specific technique, followed by sequencing to confirm the diagnosis. The results of parental gene analyses assists in obtaining a final conclusion of the diagnosis; subsequently, patients can be analyzed exclusively with this technique, avoiding the use of other techniques, in order to alleviate the high cost and greater analysis time.

The laboratory diagnosis of men with clinical indication of FXS could be performed by considering two groups: patients with a clinical suspicion of FXS, and patients with a family history of FXS. Note that this study analyzed only patients with a clinical indication of FXS. PCR-T proved to be reliable for the study of patients with a clinical suspicion of FXS; however, similar to the routine laboratory method used for the analysis of patients with a family history of FXS, PCR-P must be used to analyze these patients, as they have a greater likelihood of the presence of premutation, which is not indicated by PCR-T. Moreover, these patients run the risk of mosaicism, which may be considered normal by PCR-T.

Inconclusive results obtained by PCR-T or PCR-P must be followed by research into premutations in the breast genes of the patient in question by PCR-P, since men, necessarily, inherit the $\mathrm{X}$ chromosome from their mothers.

Following the same order, in the diagnosis of female patients, if the mother is normal, the patient is believed to be standard for FXS, having inherited the FMR1 gene normal.

All patients (both men and women) showing a family history as carriers of FXS must necessarily be evaluated by sequencing. This technique will respond with greater reliability, 
assisting in appropriate genetic counseling and treatment.

The speed and economy of PCR techniques justify their use in the diagnosis of FXS screening, even when analyzing the familial history and conducting PCR-P for maternal and/or paternal genes. The suggested strategy assumes that all individuals affected by FXS have an upward pre-mutation in the FMR1 gene. Therefore, we can discard or emphasize the suspicion of FXS by analyzing the parents of each patient diagnosed as inconclusive by PCR-P. Therefore, a specific study must be performed only in specific cases of suspected syndrome and in patients with relatives displaying the FXS pattern of mosaicism.

This approach takes into question the limitations and difficult access of families to genetic services in Brazil. PCR assays and PCR-T, and PCR-P are inexpensive, and the equipment is easily accessible compared to normal sequencing technique.

Although the use of molecular techniques has resulted in a major advance in the diagnosis of FXS, there are still economic and technical barriers hindering their usage. However, a combination of the two methods of PCR could be effective for the molecular screening for FXS.

Screening has been shown to identify the carriers of pre-mutation in the FMR1 gene; however, this method has lower sensitivity for the detection of mutated alleles in females. Therefore, it must be complemented with other techniques in specific cases.

This methodology significantly reduces the use of expensive methodologies that are difficult to standardize. Once the diagnosis of FXS is discarded, other approaches could be used to investigate less frequent causes of diabetes (mainly those forms linked to chromosome X).

This study was aimed at standardizing a diagnostic technique for FXS, and comparing two PCR techniques for the same purpose. The techniques selected in this study were PCR-T, described by Fu et al. (1991), and PCR-P - as designated in this study - developed by Saluto et al. (2005). The major difference in the PCR-P protocol is the size of the second primer used; the second primer is somewhat lower in size and facilitates the detection of the CGG repeat expansion, dispensing with costly and time-consuming procedures, such as hybridization with radioactive probes, or chemiluminescent visualization of alleles CGG large expansions, particularly in the range of pre-mutation (over 60 repetitions).

\section{Conflicts of interest}

The authors declare no conflict of interest.

\section{ACKNOWLEDGMENTS}

The authors would like to thank all informed participants of this study. Research technically and scientifically supported by Laboratório de Citogenética e Genética Molecular Humana (LaGene), the Center for Research Replicon of Pontifícia Universidade Católica de Goiás (PUC$\mathrm{GO})$, and CAPES for funding this publication.

\section{REFERENCES}

Bhogal B and Jogens TA (2010). Fragile $X$ syndrome and model organisms: identifying potential routes of therapeutic intervention. Dis. Model Mech. 3: 693-700.

Cardozo A and Soares B (2011). Habilidades sociais e o envolvimento entre pais e filhos com deficiência intelectual. Psicol. Cienc. Profissão 31: 110-119.

Collins SC, Coffee B, Benke PJ, Berry-Kravis E, et al. (2010). Array-based FMR1 sequencing and deletion analysis in patients 
with a fragile X syndrome-like phenotype. PLoS One 9476: 5-3.

Filipovic-Sadic S, Sah S, Chen L, Krosting J, et al. (2010). A novel FMR1 PCR method for the routine detection of low abundance expanded alleles and full mutations in fragile X syndrome. Clin. Chem. 56: 399-408.

Fu YH, Kuhl DP, Pizzuti A, Pieretti M, et al. (1991). Variation of the CGG repeat at the fragile X site results in genetic instability: resolution of the Sherman paradox. Cell 67: 1047-1058.

Galvan AM and Galvez R (2012). Neocortical vasculature in the Fragile X mental retardation syndrome. Brain Res. 1471: 155-161.

Hagerman R, Hoem G and Hagerman P (2010). Fragile X and autism: Intertwined at the molecular level leading to targeted treatments. Mol. Autism 1: 12.

Hall SS, Maynes NP and Reiss AL (2009). Using percentile schedules to increase eye contact in children with fragile $X$ syndrome. J. Appl. Behav. Anal. 42: 171-176.

Khaniani MS, Kalitsis P, Burgess T and Slater HR (2008). An improved diagnostic PCR assay for identification of cryptic heterozygosity for CGG triplet repeat alleles in the Fragile X gene (FMR1). Mol. Cytogenet. 1: 5 .

Kumari D and Usdin K (2010). The distribution of repressive histone modifications on silenced FMR1 alleles provides clues to the mechanism of gene silencing in fragile X syndrome. Hum. Mol. Genet. 19: 4634-4642.

Lamonica DAC, Ferraz PMDP, Ferreira AT, Prado LM, et al. (2011). Síndrome do X Frágil com variante de Dandy-Walker: estudo clínico das manifestações comunicativas orais e escritas. J. Soc. Bras. Fonoaudiol. 23: 177-182.

Queiroz MA (2006). Avaliação de pré-mutação por PCR na síndrome do X-frágil. Master's thesis, Universidade Federal de Santa Catarina, Florianópolis.

Queiroz LB (2011). Avaliaçãoda Técnicadelmuno-histoquímica (BulbodeCabelo) para Portadoresda Síndromedo X Frágil. Comparaçãocomas Técnicas Citogenéticae Molecular (PCR). Master's thesis, Faculdadede Medicina da Universidadede Brasília, Universidade de Brasília, Brasília.

Ruiz LR, Borgarello MQ, Aytes LB and Escoda CG (2009). Fragile X-syndrome: literature review and report of two cases. Med. Oral 14: 9 .

Saluto AA, Brussino F, Tassone C, Arduino C, et al. (2005). An enhanced polymerase chain reaction assay to detect pre- and full mutation alleles of the fragile $X$ mental retardation 1 gene. J. Mol. Diagn. 7: 605-612.

Stegani FC (2011). Desafios na avaliação genético-molecular de pacientes com suspeita da síndrome do X-frágil atendidos na rede pública de saúde do estado de Goiás. Master's thesis, Pontifícia Universidade Católica de Goiás, Goiânia.

Steiner CE, Guerreiro MM, Marques-de-Faria AP and Lopes-Cendes I (2005). Laboratorial diagnosis of fragile-X syndrome: experience in a sample of individuals with pervasive developmental disorders. Arq. Neuropsiquiatr. 63: 564-570.

Van Esch H (2006). The Fragile X premutation: new insights and clinical consequences. Eur. J. Med. Genet. 1: 8-49.

Vasconcelos MM (2004). Retardo mental. J. Pediatria 80: 71-82.

Yim SY, Jean BH, Yang JA and Kim HJ (2008). Fragile X syndrome in Korea: a case series and a review of the literature. J. Korean Med. Sci. 470: 6-23. 